\title{
Development of Refractive Errors-What Can We Learn From Inherited Retinal Dystrophies?
}

\section{MICHELLE HENDRIKS, VIRGINIE J.M. VERHOEVEN, GABRIËLLE H.S. BUITENDIJK, JAN ROELOF POLLING, MAGDA A. MEESTER-SMOOR, ALBERT HOFMAN, RD5000 CONSORTIUM, MAARTEN KAMERMANS, L. INGEBORGH VAN DEN BORN, AND CAROLINE C.W. KLAVER}

- PURPOSE: It is unknown which retinal cells are involved in the retina-to-sclera signaling cascade causing myopia. As inherited retinal dystrophies (IRD) are characterized by dysfunction of a single retinal cell type and have a high risk of refractive errors, a study investigating the affected cell type, causal gene, and refractive error in IRDs may provide insight herein.

- DESIGN: Case-control study.

- METHOdS: Study Population: Total of 302 patients with IRD from 2 ophthalmogenetic centers in the Netherlands. Reference Population: Population-based Rotterdam Study-III and Erasmus Rucphen Family Study $(\mathrm{N}=5550)$. Distributions and mean spherical equivalent (SE) were calculated for main affected cell type and causal gene; and risks of myopia and hyperopia were evaluated using logistic regression.

- RESULTS: Bipolar cell-related dystrophies were associated with the highest risk of SE high myopia 239.7; odds ratio (OR) mild hyperopia 263.2 , both $P<$ .0001; SE - 6.86 diopters (D) (standard deviation [SD] 6.38), followed by cone-dominated dystrophies (OR high myopia 19.5, $\mathrm{P}<.0001$; OR high hyperopia 10.7, $P=.033$; SE $-3.10 \mathrm{D}$ [SD 4.49]); rod dominated dystrophies (OR high myopia 10.1, $P<.0001$; OR high hyperopia $9.7, P=.001$; SE $-2.27 \mathrm{D}$ [SD 4.65]), and retinal pigment epithelium (RPE)-related dystrophies (OR low myopia $2.7 ; P=.001$; OR high hyperopia 5.8; $P=.025$; SE -0.10 D [SD 3.09]). Mutations in RPGR (SE - 7.63 D [SD 3.31]) and CACNA1F (SE - 5.33 D [SD 3.10]) coincided with the highest

\section{Accepted for publication Jul 10, 2017.}

From The Rotterdam Eye Hospital, Rotterdam, Netherlands (M.H., L.I.B.); Departments of Ophthalmology (V.J.M.V., G.H.S.B., J.R.P., M.A.M.-S., C.C.W.K.), Epidemiology (V.J.M.V., G.H.S.B., M.A.M.-S., A.H., C.C.W.K.), and Clinical Genetics (V.J.M.V.), Erasmus Medical Center, Rotterdam, Netherlands; Netherlands Consortium for Healthy Ageing, Netherlands Genomics Initiative, The Hague, Netherlands (A.H.); Department of Epidemiology, Harvard T.H. Chan School of Public Health, Boston, Massachusetts (A.H.); Netherlands Institute for Neuroscience, Amsterdam, Netherlands (M.K.); Department of Neurogenetics, Academic Medical Center, University of Amsterdam, Amsterdam, Netherlands (M.K.); and Department of Ophthalmology, Radboud University Medical Center, Nijmegen, Netherlands (C.C.W.K.).

*A listing of the members of the RD5000 Consortium is included in the Appendix.

Inquiries to Caroline C. W. Klaver, Erasmus Medical Center, Room Na2808, PO Box 2040, 3000 CA, Rotterdam, The Netherlands; e-mail: c.c.w. klaver@erasmusmc.nl degree of myopia and in CABP4 (SE 4.81 D [SD 0.35]) with the highest degree of hyperopia.

- CONCLUSIONS: Refractive errors, in particular myopia, are common in IRD. The bipolar synapse and the inner and outer segments of the photoreceptor may serve as critical sites for myopia development. (Am J Ophthalmol 2017;182:81-89. (C) 2017 Elsevier Inc. All rights reserved.)

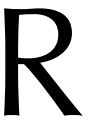

EFRACTIVE ERRORS (MYOPIA AND HYPEROPIA) ARE the most common ocular disorders worldwide and are a prominent cause of blindness. ${ }^{1}$ This highly heritable trait has been subject to many studies, and the search for genes-in particular for myopia-has been ongoing for several years. ${ }^{2,3}$ Myopia is thought to be caused by a visually evoked retina-to-sclera-signaling cascade. Various genes representing different pathways in myopia development have been discovered. ${ }^{4,5}$ These pathways include neurotransmission, retinoic acid metabolism, extracellular matrix remodeling, and eye development. Still, only a small proportion of the heritability of refractive error has been uncovered.

It is known that refractive errors are common in patients with inherited retinal dystrophies (IRD), such as retinitis pigmentosa (RP, in particular in X-linked forms ${ }^{6}$ ), congenital stationary night blindness, Stargardt disease, and Best macular dystrophy. ${ }^{7-9}$ IRDs are clinically and genetically heterogeneous, usually causing degeneration of a primary cell type, such as the retinal pigment epithelium (RPE), photoreceptors (cones and rods), or other retinal neurons. ${ }^{10}$ According to the location of retinal cell dysfunction, they can be classified into RPE-related macular dystrophies, photoreceptor dystrophies (cone- and rod-dominated dystrophies), and inner retina dystrophies (bipolar cell dysfunctions). Stargardt disease, caused by mutations in the $\mathrm{ABCA} 4$ gene, is the most common form of macular dystrophy. ${ }^{11,12}$ Other more rare RPE-related macular dystrophies are Best macular dystrophy and pattern dystrophy. Conedominated dystrophies include achromatopsia, cone dystrophies (CD), and cone-rod dystrophies (CRD). ${ }^{13}$ Rod-cone dystrophies (RCD), also known as RP, are the largest subtype of IRD, accounting for $\sim 50 \%$ of all inherited IRDs. ${ }^{14}$ Lastly, congenital stationary night blindness (CSNB) is usually caused by defective retinal signaling from the photoreceptors to the "ON" bipolar cells. ${ }^{15}$ 
IRDs may serve as naturally occurring experiments to study the specific cell types and structures involved in the development of myopia. Although several former reports refer to an increased incidence of myopia in patients with inherited retinal dystrophies, most do not include specific quantifiable data, and their spectrum of diseases is limited. $6,7,16$

Here, we studied a large group of patients with a broad spectrum of inherited IRDs. We investigated frequency and degree of refractive error as a function of affected cell type and causal gene, with the aim to detect bottlenecks for myopia development.

\section{METHODS}

- SUBJECTS: IRD patients were identified at ophthalmogenetic outpatient clinics of Erasmus Medical Center $(\mathrm{n}=$ $265)$ and the Rotterdam Eye Hospital $(n=37)$. These 2 ophthalmogenetic centers belong to the Dutch IRD registry, the RD5000 Consortium. ${ }^{17}$ The total study population consisted of 302 patients with IRD, and we identified 4 groups of primary affected cell type: RPE-related macular dystrophies (RPE; Stargardt and Best disease and PD; $\mathrm{n}=$ 77), cone-dominated dystrophies (CD; achromatopsia, $\mathrm{CRD}, \mathrm{n}=76$ ), rod-dominated dystrophies (RD; RP and RCD; $\mathrm{n}=104)$, and ON bipolar cell dysfunctions (BPCD; $n=45)$. To compare the distribution of refractive error to a general population, we used a population-based reference group $(\mathrm{n}=5550)$, a combined dataset from 2940 participants (age 45+ years) from the Rotterdam Study III (RS-III), ${ }^{18}$ and 2610 participants (age 18+ years) from the Erasmus Rucphen Family Study (ERF). ${ }^{19,20}$

Data of IRD patients enrolled in the RD5000 database were pseudonymized and personal details were only available at their ophthalmological center, which makes informed consent not obligatory. Nevertheless, we created an informed consent to obtain patient approval for data entry in the RD5000 database. Measurements in the Rotterdam Study and ERF were collected after receiving approval from the Medical Ethics Committee of the Erasmus University Medical Center, and all participants provided written informed consent in accordance with the Declaration of Helsinki.

- CLINICAL ASSESSMENT: We retrieved all clinical data from medical charts. These data included Snellen visual acuity, cycloplegic objective refraction based on autorefraction (retinoscopy was used whenever autorefraction failed) followed by subjective refraction, color vision (Hardy-Rand-Rittler color vision test or Ishihara), visual field tested by Goldmann perimetry, and electroretinographic responses according to ISCEV. ${ }^{21}$ All ophthalmic data were reviewed by retinal medical specialists with expertise in ophthalmic genetics (L.I.v.d.B., C.C.W.K.).
For RS-III and ERF (reference group) a similar protocol was used for phenotyping; all subjects underwent an ophthalmologic examination, which included noncycloplegic automated measurement of refractive error (Topcon RM-A2000 autorefractor, Tokyo, Japan), followed by subjective refraction, best-corrected visual acuity, fundus photography, and visual field perimetry (Humphrey Visual Field Analyzer; Zeiss, Oberkochen, Germany).

- MOLECULAR GENETIC ANALYSIS: In the outpatient clinic, patients with inherited IRDs were offered DNA analysis for diagnostic testing. DNA was isolated from peripheral blood lymphocytes using standard procedures. $A B C A 4$ gene mutations were analyzed in $C D$ and $R D$ patients with microarray screening from Asper Biotech (Tartu, Estonia). Genotyping was performed using the autosomal recessive and autosomal dominant RP chip from Asper Biotech (Tartu, Estonia). In patients with RP and deafness suspected for Usher syndrome an additional USH chip from Asper Biotech was used. All mutations were confirmed with Sanger sequencing. When one mutation was found with the autosomal recessive or Usher chip, the whole gene was sequenced in order to identify a second mutation, if present. X-linked CRD or X-linked RCD probands were screened for mutations in the RPGR gene. Patients clinically diagnosed with CSNB were screened for mutations in the CACNA1F, TRPM1, CABP4, and NYX gene.

- StATISTICAl ANAlysis: Spherical equivalent (SE) was calculated according to the standard formula (SE = sphere $+1 / 2$ cylinder), and the mean of both eyes was used for analysis. When data from only 1 eye were available, the SE of this eye was used. We categorized SE into low (SE from -1.5 to -3 diopters [D]), moderate (SE from -3 to $-6 \mathrm{D}$ ), and high (SE of $-6 \mathrm{D}$ or lower) myopia; emmetropia (SE from -1.5 to $+1.5 \mathrm{D}$ ); and low (SE from +1.5 to $+3 \mathrm{D}$ ), moderate (SE from +3 to $+6 \mathrm{D}$ ), and high (SE of $+6 \mathrm{D}$ or higher) hyperopia, using previously defined criteria. ${ }^{22}$

Analyses were stratified by main affected cell type (RPE, $\mathrm{CD}, \mathrm{RD}$, or BPCD) and by causal gene. Causal genes that were found in fewer than 3 patients were pooled into a single group ("other genes"). Logistic regression analyses were used to assess the risk of low, moderate, and high myopia and hyperopia vs emmetropia per disease group, using the RS-III and ERF study as the reference group, and adjusting for age and sex. Subgroup analyses (analysis of variance tests, independent samples $t$ test) were performed to compare mean SE between different causal genes, between subgroups and the reference population, between different ABCA4-related dystrophies (Stargardt, CRD, and RCD), and between RPE-related dystrophies (Stargardt, Best, pattern dystrophy). Since age has an influence on SE, we stratified analysis by age ( $<25$ years; $\geq 25$ years) and used the Student $t$ test to compare the mean SE between these 
TABLE 1. Clinical Characteristics of Our Study Population Stratified by Main Affected Cell Type of Inherited Retinal Dystrophy

\begin{tabular}{|c|c|c|c|c|c|c|c|c|}
\hline & \multicolumn{3}{|c|}{$\operatorname{RPE}(\mathrm{n}=77)$} & \multicolumn{2}{|c|}{$\mathrm{CD}(\mathrm{n}=76)$} & \multirow{2}{*}{$\frac{\mathrm{RD}(\mathrm{n}=104)}{\mathrm{RCD}}$} & \multirow{2}{*}{$\frac{\operatorname{BPCD}(n=45)}{\operatorname{CSNB}}$} & \multirow{2}{*}{$\begin{array}{c}\begin{array}{c}\mathrm{RS}+\mathrm{ERF} \\
(\mathrm{n}=5,550)\end{array} \\
\text { Reference }\end{array}$} \\
\hline & STGD & BEST & PD & Achromatopsia & CRD & & & \\
\hline $\mathrm{N}$ total & 54 & 18 & 5 & 14 & 62 & 104 & 45 & 5,550 \\
\hline \multicolumn{9}{|l|}{ Sex } \\
\hline Male, N (\%) & $22(40.7)$ & $9(50.0)$ & $1(20.0)$ & $10(71.4)$ & $40(64.5)$ & $52(50)$ & 42 (93.3) & $42(44.0)$ \\
\hline \multicolumn{9}{|l|}{ Age } \\
\hline Mean age of onset, $\mathrm{N}(\mathrm{SD})$ & $29.1(16.9)$ & $26.9(22.2)$ & $54.2(10.1)$ & $6.8(5.75)$ & $18.3(14.6)$ & $20.3(17.1)$ & $7.7(12.7)$ & na \\
\hline $\begin{array}{l}\text { Mean age at SE } \\
\text { measurement, } N(S D)\end{array}$ & $37.6(16.2)$ & $37.8(23.8)$ & $57.8(10.6)$ & $30.3(17.6)$ & $33.9(17.3)$ & $37.6(16.7)$ & $22.5(15.8)$ & $53.1(11.6)$ \\
\hline Mean SE (SD) & $-1.1(2.7)$ & $2.3(2.9)$ & $1.8(2.5)$ & $-2.9(5.0)$ & $-3.15(4.1)$ & $-2.3(4.7)$ & $-6.9(6.4)$ & $0.0(2.3)$ \\
\hline DNA sample available, N (\%) & $51(94.4)$ & $14(77.8)$ & $5(100.0)$ & $13(92.9)$ & $53(84.1)$ & $98(94.2)$ & $18(40.9)$ & na \\
\hline At least one mutation, $\mathrm{N}(\%)$ & $35(64.8)$ & $11(61.1)$ & $3(60.0)$ & $11(78.6)$ & $31(50.8)$ & $68(65.4)$ & $13(29.5)$ & na \\
\hline Genetically solved $^{a}, \mathrm{~N}(\%)$ & $16(29.6)$ & $11(61.1)$ & $3(60.0)$ & 9 (64.3) & 20 (33.3) & $41(39.4)$ & $11(25.0)$ & na \\
\hline
\end{tabular}

$\mathrm{BEST}=$ Best macular dystrophies; BPCD = bipolar cell dysfunctions; $\mathrm{CD}=$ cone-dominated dystrophies; CRD = cone-rod dystrophies; CSNB = congenital stationary night blindness; na = not applicable; $P D=$ pattern dystrophy; $R C D=$ rod-cone dystrophies; $R D=$ roddominated dystrophies; RPE = retinal pigment epithelium-related macular dystrophies; SE = spherical equivalent; STGD = Stargardt disease.

${ }^{a}$ Defined as the identification of 1 (in autosomal dominant or X-linked disease) or 2 pathogenic mutations (autosomal recessive disease)

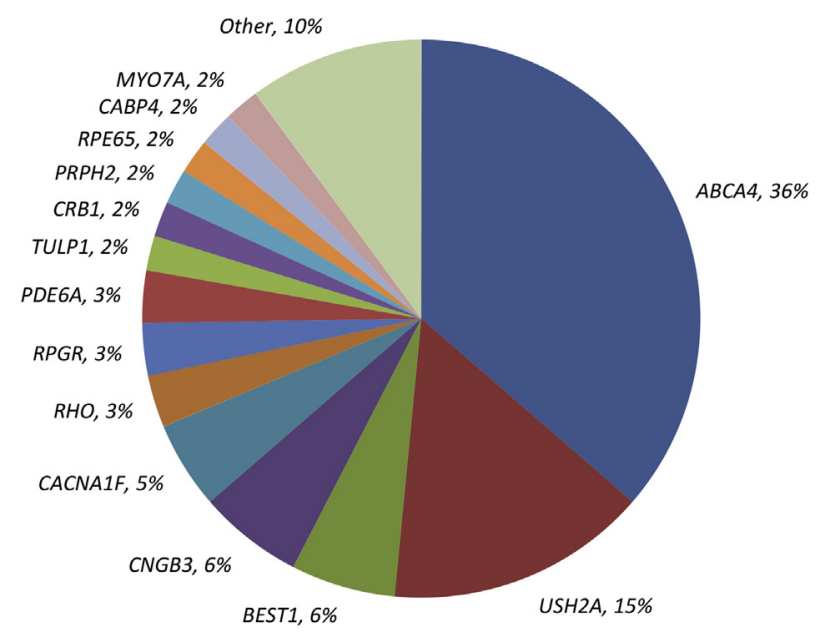

FIGURE 1. Frequency of causal genes in the study population ( $n=172$ ). The group "other" consists of various genes found in fewer than 3 subjects.

age groups. All analyses were performed using SPSS version 20 (SPSS Inc, Chicago, Illinois, USA).

\section{RESULTS}

CLINICAL CHARACTERISTICS OF THE STUDY POPULATION $(\mathrm{n}=302)$ categorized by diagnosis are summarized in Table 1. Of all patients with RPE-related macular dystrophies $(\mathrm{n}=77)$, most were diagnosed with Stargardt disease $(\mathrm{n}=54), 18$ with Best disease, and only a small group with

\begin{tabular}{lcc}
\hline \multicolumn{3}{c}{ TABLE 2. Distribution of Spherical Equivalent in "Other } \\
Genes"
\end{tabular}

pattern dystrophy $(\mathrm{n}=5)$. In the group with $\mathrm{CD}(\mathrm{n}=76)$, 15 patients had achromatopsia and 61 patients CRD. The largest group was formed by patients with $\mathrm{RD}$, including 104 RCD patients. With 45 CSNB patients, BPCD formed the smallest group.

A DNA sample was available in $83 \%$ of all included patients. In $57 \%$ of our study population at least 1 mutation was found. In total, $37 \%$ of the cases were genetically solved (autosomal recessive, autosomal dominant, or 


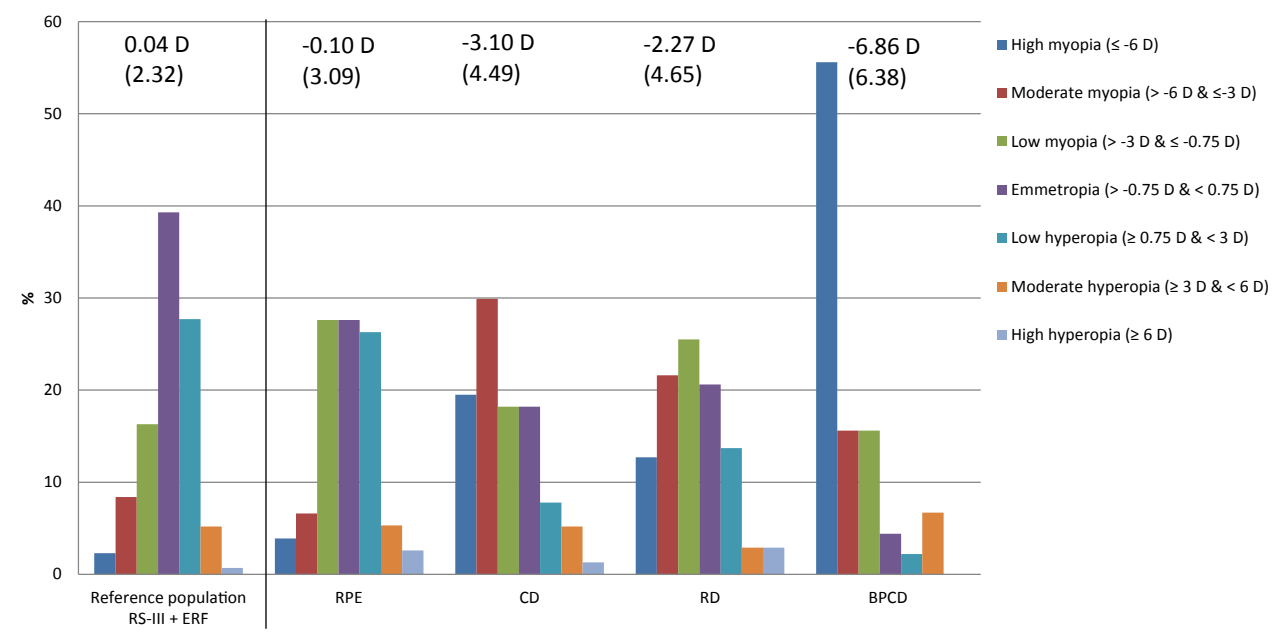

FIGURE 2. Refractive error distribution in retinal dystrophies. Percentages of subcategories of mean spherical equivalent are shown for patients with retinal pigment epithelium (RPE)-related dystrophies (RPE), cone-dominated dystrophies (CD), rod-dominated dystrophies (RD), and bipolar cell dysfunctions (BPCD), compared to our reference group (RS-III and ERF). Mean standard error $(\mathrm{SE})$ in diopters $(\mathrm{D}) \pm$ standard deviation is shown above each subgroup. RS-III = Rotterdam Study III; ERF = Erasmus Rucphen Family Study.

X-linked inherited) (Table 1). This was defined as the identification of 1 (in autosomal dominant or X-linked disease) or 2 pathogenic mutations (autosomal recessive disease). Figure 1 shows the frequency of mutations found in various genes within the subtypes of inherited retinal diseases. Genes causing the disease in fewer than 3 patients were pooled. All gene-specific data can be found in Table 2 .

The distributions of SE in our patient group and reference group are shown in Figure 2. In CD (mean SE -3.10 D [SD 4.49]), RD (mean SE -2.27 D [SD 4.65]), and BPCD (mean SE -6.86 D [SD 6.38]) the distribution was skewed toward the left (more myopic) compared to RPE-related macular dystrophies (mean SE -0.10 D [SD 3.09]) and the reference group (mean $\mathrm{SE}+0.04 \mathrm{D}$ [SD 2.32]). Figure 3 shows the risks of myopia and hyperopia per disease group, compared to the reference population. Persons with ON bipolar cell dysfunctions had the highest risk of refractive error (odds ratio [OR] high myopia 239.7 and OR mild hyperopia 263.2, both $P<.0001$ ), followed by cone-dominated dystrophies (OR high myopia 19.5, $\mathrm{P}<.0001$; and OR high hyperopia 10.7, $P=.033$ ), rod-dominated dystrophies (OR high myopia 10.1, $P<0.0001$; OR high hyperopia 9.7, $P=0.001$ ), and RPE-related dystrophies (OR low myopia $2.7 ; P=.001$; and $O R$ high hyperopia $5.8 ; P=.025)$. A subgroup analysis within the RPE-related macular dystrophies showed a significant $(P<.0001)$ difference in mean SE between Stargardt patients $(\mathrm{n}=54$; mean SE $-1.10 \mathrm{D}$ [SD 2.68]) and Best patients $(\mathrm{n}=18$; mean $\mathrm{SE}+2.34 \mathrm{D}$ [SD 2.91]).

Table 3 shows the mean SE stratified by age at first visit. Mean age at first visit in our study population $(\mathrm{n}=302)$ was 35 years (SD 18), ranging from 0 to 80 years and differing between subtypes. Only patients with rod-dominated dystrophies were significantly $(P=.027)$ more myopic (mean SE - 2.83 D [SD 4.65]) at age $>25$ years compared to $\leq 25$ years (mean SE -0.49 D [SD 4.22]).

Figure 4 shows the SE distribution for various genes causing inherited retinal dystrophies, and their location in the retina. Most genes (9 out of 14) coincided with myopia. The ABCA4 gene formed the most common disease-causing gene $(\mathrm{n}=62$; mean $\mathrm{SE}-2.02 \mathrm{D}$ [SD 3.71]). Mutations in the ABCA4 did not cause statistically different degrees of myopia depending on the diagnosis, that is, Stargardt disease (SE - 1.50 [SD 2.85]) and conerod dystrophy (SE -2.72 [SD 4.11]), $P=.493$. Patients with mutations in the BEST1 gene $(n=11)$ had a mean $\mathrm{SE}$ of +1.84 D [SD 2.95], which is significantly higher than the mean SE of the ABCA4 $(n=62 ; P=.051)$ or the RPGR gene $(\mathrm{n}=6 ; P=.001)$. Patients with mutations in the RPGR gene $(\mathrm{n}=6)$ were the most myopic (mean SE $-7.63 \mathrm{D}$ [SD 3.31) of all, followed by CACNA1F $(\mathrm{n}=8$; mean SE -5.33 D [SD 3.10]). Patients with mutations in the CABP4 gene $(n=3)$ had the highest degree of hyperopia (mean SE 4.81 D [SD 0.35]).

\section{DISCUSSION}

WE STUDIED REFRACTIVE ERROR IN 302 PATIENTS WITH IRD who consecutively entered a national database, and found that genes involved in these diseases often coincide with either myopia or hyperopia. Our results show that in particular BPCD is associated with high myopia and high hyperopia, and CD and RP as a group mostly lead to mild myopia. 


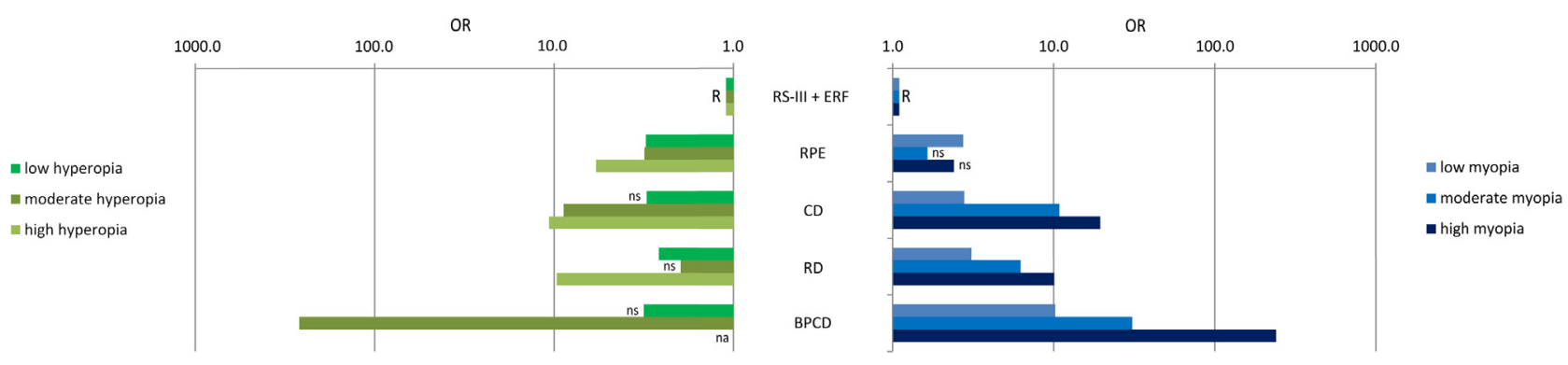

FIGURE 3. Risk of myopia and hyperopia per main affected cell type. This plot shows odds ratios of several degrees of myopia (Right) and hyperopia (Left) vs emmetropia per disease group. The RS-III and ERF study were used as the reference group (R), and analyses were adjusted for age and sex. The BPCD group was too small to calculate an odds ratio for high hyperopia (na). OR = odds ratio; RSIII = Rotterdam Study III; ERF = Erasmus Rucphen Family Study; RPE = retinal pigment epithelium-related macular dystrophies; $\mathrm{CD}=$ cone-dominated dystrophies; $\mathrm{RD}=$ rod-dominated dystrophies; $\mathrm{BPCD}=$ bipolar cell dysfunction; na $=$ not applicable; ns = nonsignificant.

TABLE 3. Spherical Equivalent Stratified by Age

\begin{tabular}{|c|c|c|c|c|c|c|c|}
\hline & \multicolumn{2}{|c|}{$<10$ Years } & \multicolumn{2}{|c|}{$10-25$ Years } & \multicolumn{2}{|c|}{$>25$ Years } & \multirow[b]{2}{*}{$P$ Trend } \\
\hline & $\mathrm{N}$ & Mean SE ( \pm SD) & $\mathrm{N}$ & Mean SE ( $( \pm S D)$ & $\mathrm{N}$ & Mean SE ( \pm SD) & \\
\hline $\operatorname{RPE}(\mathrm{n}=77)$ & 5 & $3.9(2.9)$ & 15 & $-0.86(1.78)$ & 57 & $-0.25(3.15)$ & .292 \\
\hline$C D(n=76)$ & 8 & $-0.23(7.92)$ & 20 & $-2.86(3.16)$ & 48 & $-3.68(4.13)$ & .023 \\
\hline $\mathrm{RD}(\mathrm{n}=104)$ & 4 & $1.94(2.23)$ & 21 & $-0.95(4.39)$ & 79 & $-2.83(4.66)$ & .076 \\
\hline $\operatorname{BPCD}(n=45)$ & 11 & $-3.84(4.17)$ & 18 & $-6.52(6.28)$ & 16 & $-9.34(7.05)$ & .959 \\
\hline
\end{tabular}

This suggests that bipolar cells may be important players in myopia development.

Although systematic reports are lacking, occasional case series have reported refractive errors in patients with IRD. Mild refractive errors have been described for Stargardt and Best disease ${ }^{7,9}$; more severe refractive errors for CSNB and for RP caused by RPGR and RP1. ${ }^{6,16,23-26}$ Our comprehensive analyses show that RPE-related dystrophies such as Stargardt, Best, and pattern dystrophy indeed mostly have mild refractive errors. Photoreceptor disorders have more variability in refractive error but are also mildly myopic on average; CDs have a somewhat higher frequency of moderate myopia than RP. Our study indicates that BPCD predominantly leads to severe refractive errors, and notably, the direction of SE is dependent on the causal gene.

Our study has a unique design in myopia research. We selected patients with a known primary defect in the retina and studied the effect on refractive error. We focused on several affected cell types as well as on causal genes within each cell type. Because myopia develops at childhood and early youth, we stratified for age and found differential effects even in those with a very early onset. Our study is the only systematic investigation on refractive error and IRD to date, and it includes a broad spectrum of diagnoses. In addition, we had access to large population-based studies, which we used as a reference population in the evaluation of risk of refractive error. Our study has drawbacks as well. Although our total sample size was substantial, subgroup analyses were limited by small numbers. The age ranges of the 2 reference populations differed; however, comparison to the single populations did not significantly alter the risk estimates (data not shown). Lastly, our IRD patients lacked data on established risk factors for myopia such as familial occurrence of myopia and educational level, as well as the age of onset of myopia.

A striking finding of our study was that malfunctioning bipolar cell synapses can lead to high myopia. Bipolar cells are known to transmit signals from photoreceptors to amacrine and ganglion cells. ${ }^{27}$ They can be divided by $\mathrm{ON}$ and OFF subtypes. ON bipolar cells depolarize, whereas OFF bipolar cells hyperpolarize when the retina is stimulated by light. Rod signal transmission primarily occurs through $\mathrm{ON}$ bipolar cells, whereas cones connect with both ON and OFF bipolar cells. BPCD are known to affect the ON bipolar cells. Whether a dysfunctional OFF bipolar 


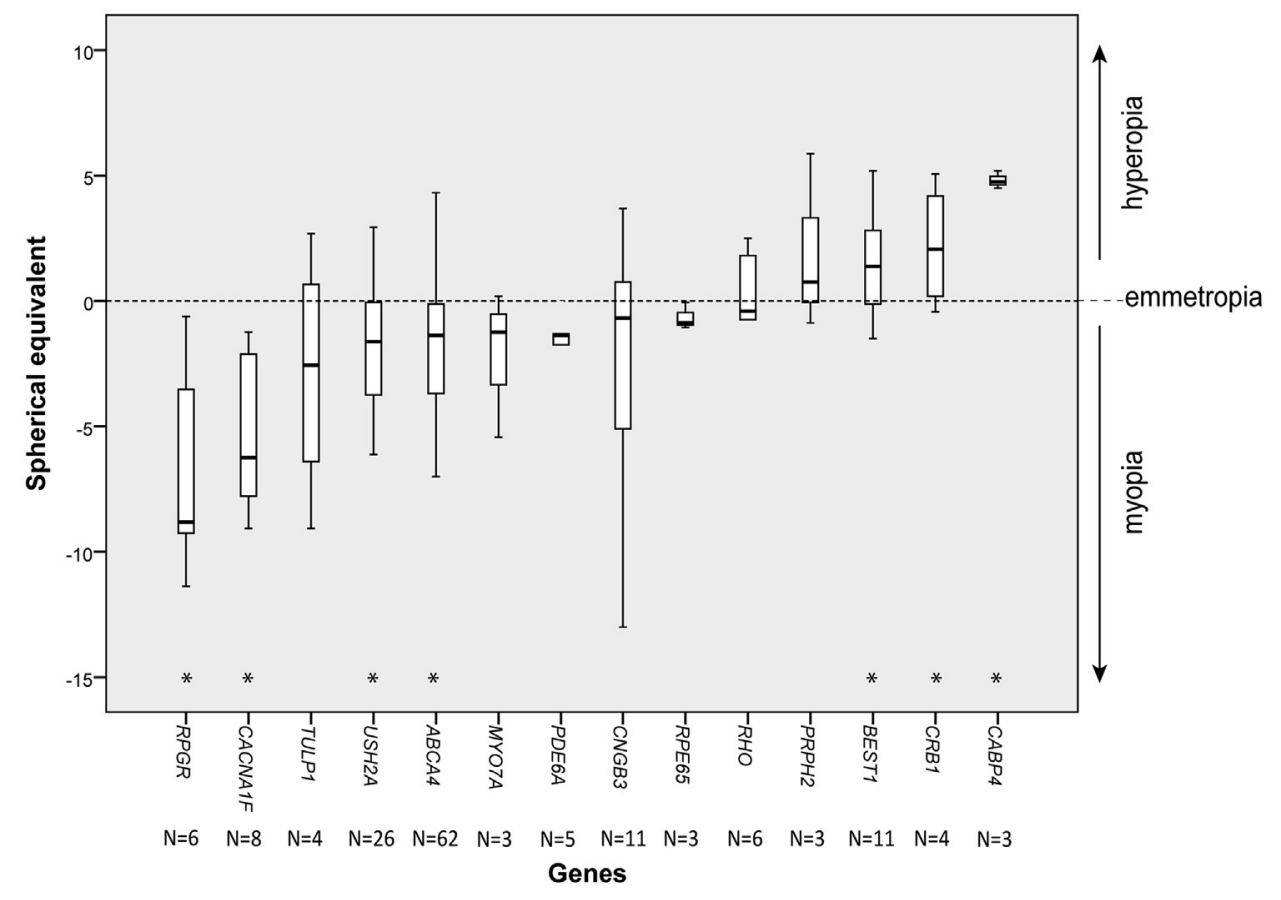

FIGURE 4. Distribution of refractive errors for gene-specific inherited retinal dystrophies. Top: Box plots of the distribution of spherical equivalent (in diopters) on $y$-axis per specific causal gene on $\mathrm{x}$-axis. *, significantly different from the reference population at $P$ value $<.05$ (independent samples $t$ test). Causal genes that were found in fewer than 3 patients were not included in this figure, but their standard error measurements can be found in Table 2. Bottom: Localization of retinal dystrophy gene products in the retina. In green: cone-specific genes. In red: rod-specific genes.

synapse causes refractive errors is unknown, since gene mutations in these cells are lethal and not a cause of IRD. Therefore, this study can only make conclusions about the role of $\mathrm{ON}$ bipolar cells in development of myopia.

If we take a closer look at genes causing BPCD, our study shows that mutations in CACNA1F, NYX, and TRPM1 often coincide with high myopia, whereas mutations in CAPB4 coincide with high hyperopia. CACNA1F is a presynaptic Ca channel present in the rod; TRPM1 and NYX are essential components of the postsynaptic glutamate receptor complex at the ON bipolar cell dendrites. ${ }^{25,28,29}$ CACNA1F and CAPB4 are both involved in the calcium-dependent release of glutamate at the photoreceptor synapse, whereas the latter 2 genes are involved in an intracellular signaling cascade converting the glutamate receptor activation into a voltage response of the $\mathrm{ON}$ bipolar cell. ${ }^{25,29}$ CAPB4 is a calcium binding protein located in the presynaptic terminal of cones. ${ }^{25,29-31}$ Mutation in CABP4 leads to photophobia rather than nyctalopia and is considered a cone synaptic disorder. ${ }^{32}$ This suggests that the rod-specific ON bipolar cell routing could lead to myopia, whereas cone-specific ON bipolar cell routing leads to hyperopia.

Genes affecting photoreceptors can cause various refractive errors. Mutations in RPGR, which is located in the connecting cilium and is involved in microtubular transport, cause high myopia, whereas mutations in USH2A, which is located at the apical side of the inner segment and is involved in the maintenance of the photoreceptor, cause only mild myopia. Mutations involved in phototransduction genes do not show consistent associations with refractive errors, although they rarely lead to emmetropia. Thus, the critical site for myopia in photoreceptors appears to be the transport area between the inner and outer segment.

The currently known genes for refractive error show some striking overlap with genes for IRD. ${ }^{4,33}$ Tophits have been found in or near genes involved in the visual cycle and retinoic acid metabolism, that is, common variants in RDH5 (encoding retinol dehydrogenase 5) and RGR (encoding the retinal $G$ protein-coupled receptor). ${ }^{4,33}$ Mutations in $\mathrm{RDH} 5$ cause a progressive cone dystrophy ${ }^{34,35}$ and fundus albipunctatus, ${ }^{26,36}$ and mutations in $R G R$ are involved in retinitis pigmentosa. ${ }^{37,38}$ Another interesting genomic locus includes CACNA1D (encoding a voltage-sensitive calcium channel), ${ }^{33}$ which shows great similarity with the CACNA1F gene mentioned earlier. Both genes encode an alpha subunit in the L-type calcium channel, localized in the presynaptic ribbon terminals of photoreceptors. Lastly, GRIA4 (encoding the ionotropic AMPA glutamate receptor GluR4) encodes a glutamate-gated ion channel that mediates fast synaptic excitatory neurotransmission, is present in the retina, and is crucial for 


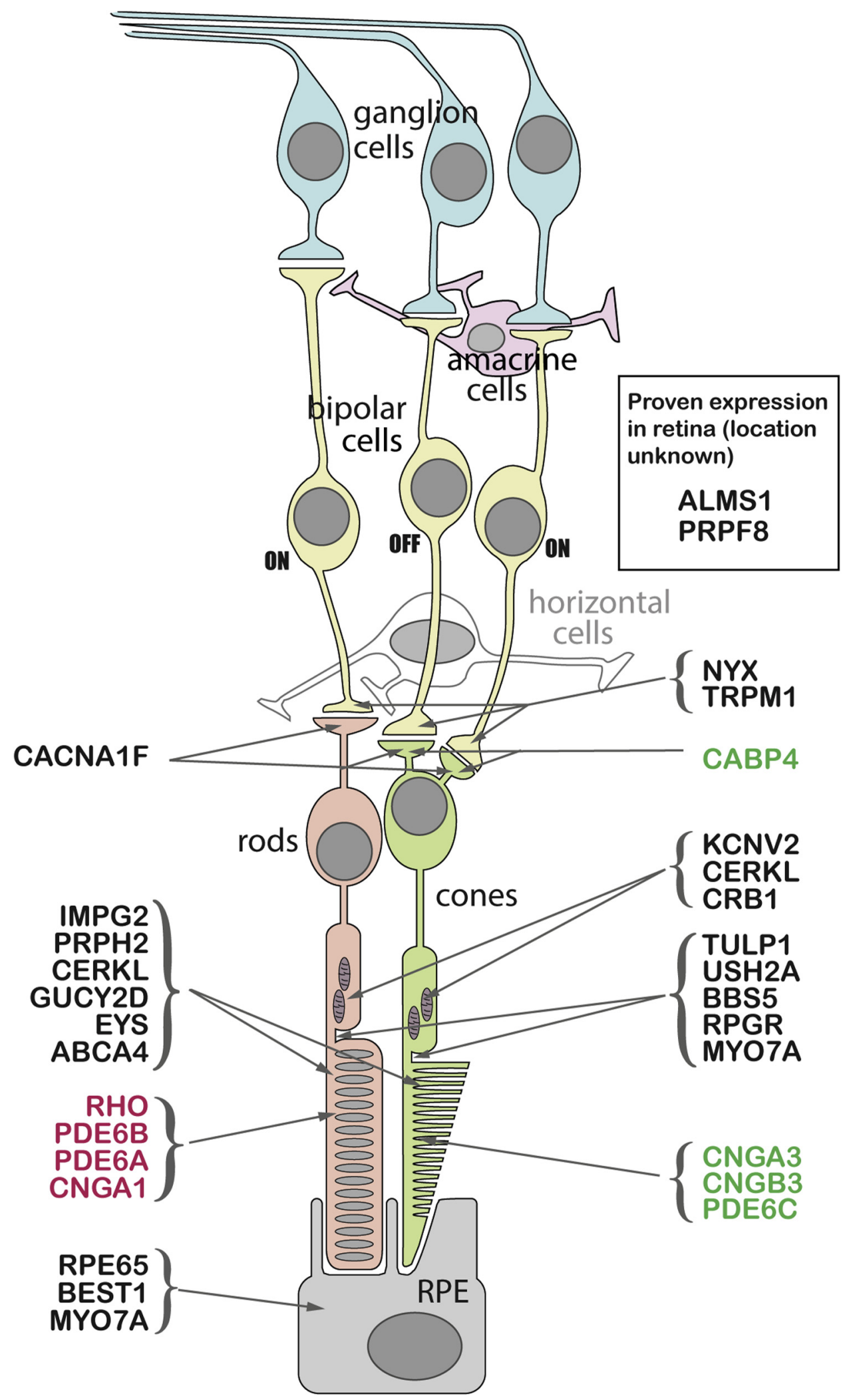

FIGURE 4. (continued). 
emmetropization. ${ }^{39-42}$ We speculate that mutations in these IRD genes cause retinal dystrophies, whereas common genetic variants within these genes may be clinically significant as myopia.

In conclusion, we showed that many genes involved in IRD coincide with myopia. Most genes cause a relatively mild myopia, but several genes causing BPCD and RP particularly predispose to high myopia. We determined critical sites for refractive error development: transport between inner and outer segment of the photoreceptor, calcium-dependent glutamate release by photoreceptors, and bipolar neurotransmission and routing. These retinal sites are candidates for more in-depth investigation by future functional studies of myopia.

FUNDING/SUPPORT: THIS STUDY WAS SUPPORTED BY A HORIZON2020 ERC CONSOLIDATOR GRANT (648268 TO C.C.W.K.), NWO Investments (175.010.2005.011, 911-03-012 to the Rotterdam Study), the Netherlands Genomics Initiative (NGI)/NWO (050-060-810 to the Rotterdam Study), Erasmus Medical Center and Erasmus University, Rotterdam, The Netherlands, Netherlands Organization for Health Research and Development (ZonMw), UitZicht, Stichting Combined Ophthalmic Research Rotterdam (CORR), the Research Institute for Diseases in the Elderly (014-93-015, RIDE2), the Ministry of Education, Culture and Science, the Ministry for Health, Welfare and Sports, the European Commission (DG XII), the Municipality of Rotterdam, the Netherlands Genomics Initiative/NWO, Center for Medical Systems Biology of NGI, Lijf en Leven, MD Fonds, Henkes Stichting, Stichting Nederlands Oogheelkundig Onderzoek, Swart van Essen, Bevordering van Volkskracht, Blindenhulp, Landelijke Stichting voor Blinden en Slechtzienden, Rotterdamse Vereniging voor Blindenbelangen, OOG, Algemene Nederlandse Vereniging ter Voorkoming van Blindheid, the Rotterdam Eye Hospital Research Foundation, and Erasmus Trustfonds. The RD5000 consortium is supported by the Stichting A.F. Deutman Oogheelkunde Researchfonds, Landelijke Stichting voor Blinden en Slechtzienden, MD Fonds, Stichting Nederlands Oogheelkundig Onderzoek, Rotterdamse Stichting Blindenbelangen, Stichting ter Verbetering van het Lot der Blinden, Algemene Nederlandse Vereniging ter Voorkoming van Blindheid, Oogfonds, and Novartis Fonds-Stichting Steunfonds UitZicht. RD5000 is based on Ophthabase, developed by the Institute for Ophthalmic Research, Tübingen, Germany, as part of the EVI-GENORET Project. Financial Disclosures: Caroline C.W. Klaver received in-kind research funding from Topcon; she is on the advisory board of Novartis, Bayer, and Thea Pharma (all in the Netherlands). The following authors have no financial disclosures: Michelle Hendriks, Virginie J.M. Verhoeven, Gabriëlle H.S. Buitendijk, Jan Roelof Polling, Magda A. Meester-Smoor, Albert Hofman, Maarten Kamermans, and L. Ingeborgh van den Born. All authors attest that they meet the current ICMJE criteria for authorship.

Other Acknowledgments: The authors thank all members of the RD5000 consortium (www.RD5000.nl) for their valuable contributions.

\section{REFERENCES}

1. Kempen JH, Mitchell P, Lee KE, et al. The prevalence of refractive errors among adults in the United States, Western Europe, and Australia. Arch Ophthalmol 2004;122(4): 495-505.

2. Wojciechowski R. Nature and nurture: the complex genetics of myopia and refractive error. Clin Genet 2011;79(4): 301-320.

3. Stambolian D. Genetic susceptibility and mechanisms for refractive error. Clin Genet 2013;84(2):102-108.

4. Kiefer AK, Tung JY, Do CB, et al. Genome-wide analysis points to roles for extracellular matrix remodeling, the visual cycle, and neuronal development in myopia. PLoS Genet 2013;9(2):e1003299.

5. Verhoeven VJ, Hysi PG, Wojciechowski R, et al. Genomewide meta-analyses of multiancestry cohorts identify multiple new susceptibility loci for refractive error and myopia. Nat Genet 2013;45(3):314-318.

6. Sieving PA, Fishman GA. Refractive errors of retinitis pigmentosa patients. $\mathrm{Br}$ J Ophthalmol 1978;62(3): 163-167.

7. Doka DS, Fishman GA, Anderson RJ. Refractive errors in patients with fundus flavimaculatus. Br J Ophthalmol 1982;66(4): 227-229.

8. Renner AB, Tillack H, Kraus H, et al. Late onset is common in best macular dystrophy associated with VMD2 gene mutations. Ophthalmology 2005;112(4):586-592.

9. Bard LA, Cross HE. Genetic counseling of families with Best macular dystrophy. Trans Sect Ophthalmol Am Acad Ophthalmol Otolaryngol 1975;79(6):OP865-OP873.

10. Bird AC. Retinal photoreceptor dystrophies LI. Edward Jackson Memorial Lecture. Am J Ophthalmol 1995;119(5): $543-562$.
11. Blacharski PA. Fundus flavimaculatus. In: Newsome DA, ed. Retinal Dystrophies and Degenerations. New York: Raven; 1988:135-159.

12. Allikmets R, Singh N, Sun H, et al. A photoreceptor cellspecific ATP-binding transporter gene (ABCR) is mutated in recessive Stargardt macular dystrophy. Nat Genet 1997; 15(3):236-246.

13. Simunovic MP, Moore AT. The cone dystrophies. Eye (Lond) 1998;12(Pt 3b):553-565.

14. Daiger SP, Sullivan LS, Bowne SJ. Genes and mutations causing retinitis pigmentosa. Clin Genet 2013;84(2):132-141.

15. Traboulsi EI, Leroy BP, Zeitz C. Congenital stationary night blindness. In: Traboulsi EI, ed. Genetic Disease of the Eye, Vol 2012. New York: Oxford University Press; 2012:476-478.

16. Thiadens AA, Phan TM, Zekveld-Vroon RC, et al. Clinical course, genetic etiology, and visual outcome in cone and cone-rod dystrophy. Ophthalmology 2012;119(4):819-826.

17. van Huet RA, Oomen CJ, Plomp AS, et al. The RD5000 database: facilitating clinical, genetic, and therapeutic studies on inherited retinal diseases. Invest Ophthalmol Vis Sci 2014; 55(11):7355-7360.

18. Hofman A, Darwish Murad S, van Duijn CM, et al. The Rotterdam Study: 2014 objectives and design update. Eur J Epidemiol 2013;28(11):889-926.

19. Pardo LM, MacKay I, Oostra B, van Duijn CM, Aulchenko YS. The effect of genetic drift in a young genetically isolated population. Ann Hum Genet 2005;69(Pt 3): 288-295.

20. Aulchenko YS, Heutink P, Mackay I, et al. Linkage disequilibrium in young genetically isolated Dutch population. Eur J Hum Genet 2004;12(7):527-534.

21. McCulloch DL, Marmor MF, Brigell MG, et al. ISCEV standard for full-field clinical electroretinography (2015 update). Doc Ophthalmol 2015;130(1):1-12. 
22. Verhoeven VJ, Buitendijk GH, Rivadeneira F, et al. Education influences the role of genetics in myopia. Eur J Epidemiol 2013;28(12):973-980.

23. Fishman GA, Farber MD, Derlacki DJ. X-linked retinitis pigmentosa. Profile of clinical findings. Arch Ophthalmol 1988;106(3):369-375.

24. Lee SH, Yu HG, Seo JM, et al. Hereditary and clinical features of retinitis pigmentosa in Koreans. J Korean Med Sci 2010;25(6):918-923.

25. Bijveld MM, Florijn RJ, Bergen AA, et al. Genotype and phenotype of 101 Dutch patients with congenital stationary night blindness. Ophthalmology 2013;120(10):2072-2081.

26. Chassine T, Bocquet B, Daien V, et al. Autosomal recessive retinitis pigmentosa with RP1 mutations is associated with myopia. Br J Ophthalmol 2015;99(10):1360-1365.

27. Euler T, Haverkamp S, Schubert T, Baden T. Retinal bipolar cells: elementary building blocks of vision. Nat Rev Neurosci 2014;15(8):507-519.

28. Okawa H, Sampath AP. Optimization of single-photon response transmission at the rod-to-rod bipolar synapse. Physiology (Bethesda) 2007;22:279-286.

29. van Genderen MM, Bijveld MM, Claassen YB, et al. Mutations in TRPM1 are a common cause of complete congenital stationary night blindness. Am J Hum Genet 2009;85(5):730-736.

30. Berntson A, Taylor WR, Morgans CW. Molecular identity, synaptic localization, and physiology of calcium channels in retinal bipolar cells. J Neurosci Res 2003;71(1):146-151.

31. Littink KW, van Genderen MM, Collin RW, et al. A novel homozygous nonsense mutation in CABP4 causes congenital cone-rod synaptic disorder. Invest Ophthalmol Vis Sci 2009; 50(5):2344-2350.

32. Khan AO. CABP4 mutations do not cause congenital stationary night blindness. Ophthalmology 2014;121(3):e15.

33. Verhoeven VJ, Hysi PG, Saw SM, et al. Large scale international replication and meta-analysis study confirms association of the $15 \mathrm{q} 14$ locus with myopia. The CREAM consortium. Hum Genet 2012;131(9):1467-1480.

34. Wang NK, Chuang LH, Lai CC, et al. Multimodal fundus imaging in fundus albipunctatus with RDH5 mutation: a newly identified compound heterozygous mutation and review of the literature. Doc Ophthalmol 2012;125(1):51-62.

35. Nakamura M, Hotta Y, Tanikawa A, Terasaki H, Miyake Y. A high association with cone dystrophy in Fundus albipunctatus caused by mutations of the RDH5 gene. Invest Ophthalmol Vis Sci 2000;41(12):3925-3932.

36. Yamamoto H, Simon A, Eriksson U, Harris E, Berson EL, Dryja TP. Mutations in the gene encoding 11-cis retinol dehydrogenase cause delayed dark adaptation and fundus albipunctatus. Nat Genet 1999;22(2):188-191.

37. Wang Q, Chen Q, Zhao K, Wang L, Traboulsi EI. Update on the molecular genetics of retinitis pigmentosa. Ophthalmic Genet 2001;22(3):133-154.

38. Bernal S, Calaf M, Garcia-Hoyos M, et al. Study of the involvement of the RGR, CRPB1, and CRB1 genes in the pathogenesis of autosomal recessive retinitis pigmentosa. J Med Genet 2003;40(7):e89.

39. Beyer B, Deleuze C, Letts VA, et al. Absence seizures in $\mathrm{C} 3 \mathrm{H} /$ $\mathrm{HeJ}$ and knockout mice caused by mutation of the AMPA receptor subunit Gria4. Hum Mol Genet 2008;17(12):1738-1749.

40. Connaughton V. Glutamate and glutamate receptors in the vertebrate retina. In: Kolb H, Fernandez E, Nelson R, eds. Webvision: The Organization of the Retina and Visual System; 1995. University of Utah Health Sciences Center; Salt Lake City (UT).

41. Yang J, Nemargut JP, Wang GY. The roles of ionotropic glutamate receptors along the $O n$ and Off signaling pathways in the light-adapted mouse retina. Brain Res 2011;1390: 70-79.

42. Smith EL 3rd, Fox DA, Duncan GC. Refractive-error changes in kitten eyes produced by chronic on-channel blockade. Vision Res 1991;31(5):833-844.

\section{APPENDIX}

RD5000 Consortium: Department of Ophthalmology, Radboud University Medical Center, Nijmegen: Ramon A. van Huet, B. Jeroen Klevering, Nathalie M. Bax, Stanley Lambertus, Caroline C.W. Klaver, Carel B. Hoyng; Department of Human Genetics, Netherlands Radboud Institute for Molecular Life Sciences, Radboud University Medical Center, Nijmegen: Clasien J. Oomen, Wendy A. van Zelst-Stams, Frans P. Cremers; Department of Clinical Genetics, Academic Medical Center, Amsterdam: Astrid S. Plomp, Mary J. van Schooneveld; Bartiméus, Institute for the Visually Impaired, Zeist: Mies M. van Genderen, José Schuil, F. Nienke Boonstra; Department of Ophthalmology, Academic Medical Center, Amsterdam: Reinier O. Schlingemann, Arthur A. Bergen; Department of Ophthalmology \& Epidemiology, Erasmus Medical Center, Rotterdam: Caroline C.W. Klaver, Laurence Pierrache, Magda MeesterSmoor; The Rotterdam Eye Hospital, Rotterdam: L. Ingeborgh van den Born; Department of Ophthalmology, Leiden University Medical Center, Leiden, Camiel J. Boon; Department of Ophthalmology, University Medical Centre Groningen, University of Groningen: Jan W.R. Pott; Department of Ophthalmology, University Medical Center Utrecht: Redmer van Leeuwen; Department of Medical Genetics, University Medical Center Utrecht: Hester Y Kroes; Department of Ophthalmology, Free University Medical Center, Amsterdam: Yvonne de Jong-Hesse 